\section{Ectopic Geographic Lingua}

Keywords: Geographic tongue; Developmental anomalies; Ectopic

\section{Abstract}

Oral cavity has always been a victim of many developmental and acquired disorders and few of them known and few unknown. Inspite of many theories proposed mystery continues. Tongue the muscular organ of oral cavity undergoes various physiologic and pathologic changes. Ectopic geographic linguais one amongst the many changes documented.

\section{Introduction}

Geographic tongue was first described by Rayer in the year 1831. It is a benign condition that occurs in up to $3 \%$ of the general population. Lesion is asymptomatic in nature however, some patients report increased sensitivity to hot and spicy foods, etiology for which is still unclear [1-3]. Inspite of many terminologies a self-explanatory name based on pathophysiology and clinical presentation "Ectopic geographic lingua" or EGL was considered, were ectopic means and abnormal place, geographic means appearance of map and lingua is a latin meaning of tongue. Here in we report a case of EGL in a female patient.

\section{Case Report}

A 21 year old female patient reported to the department with a chief complaint of deposits on her teeth. Past medical and dental history was non-contributory. Patient gave no history of deleterious habits. Extra oral examination revealed no significant changes. Intra oral examination revealed deposits on the surfaces of teeth. Dorsal aspect of the tongue revealed mapping on the surface with well demarcated areas of depapillation. Surface of the lesion is raised with evidence of migration to the tip of the tongue (Figure 1). Considering the history and clinical examination a provisional diagnosis of ectopic geographic lingua was considered. Scaling was done and oral hygiene instructions were given. Candid mouth paint application twice daily was recommended to prevent opportunistic infections.

\section{Discussion}

EGL is an inflammatory condition of the mucous membrane

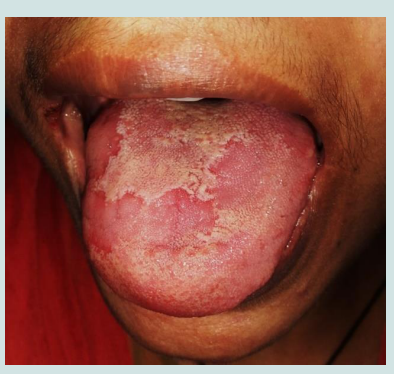

Figure 1: Map like appearance on dorsal aspect of the tongue.

\section{Journal of Oral Biology}

Siddharth Hanamasagar, Vijayendranath Nayak S*, Girish YR, Raghavendra Kini, Prasanna Kumar Rao Gowri P. Bhandarkar and Roopashri Rajesh Kashyap

Department of Oral Medicine and Radiology, A J Institute of Dental Sciences, India

\section{${ }^{*}$ Address for Correspondence}

Vijayendranath Nayak S, Department of Oral Medicine and Radiology, A J Institute of Dental Sciences, NH-66, Mangaluru, Karnataka, India, Tel: +918197588777; E-mail: drnayakomr@ gmail.com

Submission: 12 March, 2018

Accepted: 03 April, 2018

Published: 09 April, 2018

Copyright: () 2018 Nayak SV, et al. This is an open access article distributed under the Creative Commons Attribution License, which permits unrestricted use, distribution, and reproduction in any medium, provided the original work is properly cited.

of the tongue, usually seen on the dorsal surface. The etiology and pathogenesis of EGL are still poorly understood, yet psychological stress, vitamin deficiency, hormonal imbalance and other factors like smoking and tobacco use are considered to be the possible cause for this benign lesion. EGL affects males and females and is noted to be more prominent in adults than in children $[1,3,4]$.

EGL is usually asymptomatic in nature. Asymptomatic presentation of the lesion makes treatment simpler. Reassurance to the patient should be of great importance, Psychological monitoring also plays a major role. In case of burning sensation on consumption of spicy food, as reported in few reports, topical anaesthetics should be prescribed $[4,5]$.

\section{Conclusion}

Educating the patient is of utmost importance in treating the patients with EGL. More and more researches should be carried out by health care professionals with regular follow up so that exact etiology could be ruled out and accurate treatment can be provided. As of now Ectopic geographic lingua remains to be a harmless mystery.

\section{References}

1. Kleinman DV, Swango PA, Pindborg JJ (1994) Epidemiology of oral mucosa lesions in United States schoolchildren: 1986-87. Community Dent Oral Epidemiol 22: 243-253.

2. Holla VA, Laxmikanth C, Shenai PK (2012) Benign migratory glossitis treatment dilemma. Clin Dent 6: 22-25.

3. Shulman JD (2005) Prevalence of oral mucosal lesions in children and youths in the USA. Int J Paediatr Dent 15: 89-97.

4. Greenberg MS, Glick M, Ship JA (2008) Burket's oral medicine (11 $11^{\text {th }}$ edn). BC Decker Inc, Hamilton, Ontario, Canada, USA, pp. 103-104.

5. Peter C, Jelinek G, Everitt I, Browne G, Raftos J (2006) Textbook of Paediatric Emergency Medicine. E Isevier, Spain. 